Szarpak Julita, Bator Damian, Wójcik Magdalena, Nieścior Hubert, Dąbrowska Justyna, Milanowska Joanna. The influence of perinatal and postpartum depression on child development and its functioning in adult life. Journal of Education, Health and Sport. 2020;10(9):241-247. eISSN 2391-8306. DOI http://dx.doi.org/10.12775/JEHS.2020.10.09.026

https://apcz.umk.pl/czasopisma/index.php/JEHS/article/view/JEHS.2020.10.09.026

https://zenodo.org/record/4019708

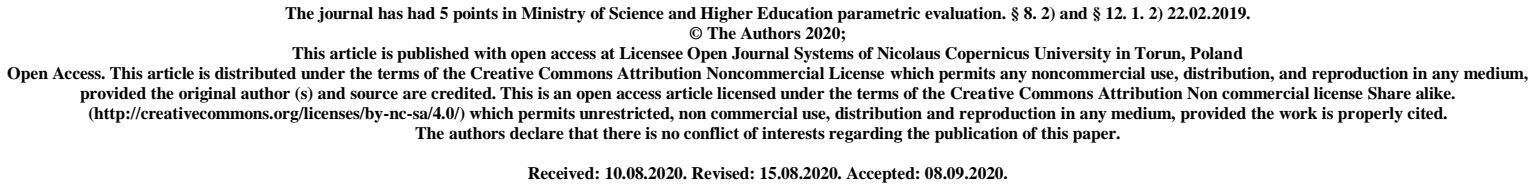

\title{
The influence of perinatal and postpartum depression on child development and its functioning in adult life
}

\author{
Julita Szarpak, Damian Bator, Magdalena Wójcik, Hubert Nieścior, \\ Justyna Dąbrowska, Joanna Milanowska
}

Julita Szarpak ${ }^{(1)}$ e-mail: julita.szarpak@ gmail.com

ORCID: https://orcid.org/0000-0002-5091-0235

Damian Bator ${ }^{(1)}$ e-mail: bat199979@gmail.com

ORCID: https://orcid.org/0000-0002-8464-932X

Hubert Nieścior ${ }^{(1)}$ e-mail: hniescior@gmail.com

ORCID: https://orcid.org/0000-0002-4709-4396

Magdalena Wójcik ${ }^{(1)}$ e-mail: magdalena.wojcik967@gmail.com

ORCID: https://orcid.org/0000-0002-0999-6284

Justyna Dąbrowska ${ }^{(1)}$ e-mail: jdabrowska00@gmail.com

ORCID: https://orcid.org/0000-0002-1356-6965

Joanna Milanowska ${ }^{(2)}$ e-mail: joannamilanowska@umlub.pl

ORCID: https://orcid.org/0000-0001-9741-1583

${ }^{(1)}$ Students Science Club at the Department of Applied Psychology, Medical University of Lublin, Aleje Racławickie 1, 20-059 Lublin, Poland

${ }^{(2)}$ Department of Applied Psychology, Medical University of Lublin 


\section{Abstract}

Introduction and purpose: During pregnancy, the physiology of the mother's organism undergoes many changes, and this also applies to the sphere of mental health. Difficulties in adapting to the new situation, metabolic, genetic and environmental factors may predispose expectant mothers to develop depression spectrum disorders. The purpose of this study is, based on the available data, to summarize the consequences of maternal depressive disorder development during pregnancy and postpartum.

Brief description of the state of knowledge: The development of mental disorders by a pregnant woman has a documented negative impact on the course of pregnancy and on the maturation of the fetus. The consequences of excessive stress, anxiety and depression during pregnancy include, among others, an increased risk of premature birth, abnormalities in the development of the nervous system of the fetus, and difficulties in acquiring speech skills in the future life. In mothers, perinatal depression increases the risk of severe psychosis or substance abuse such as alcohol and drugs.

Conclusions: A number of serious complications, both for a woman and a child, related to the occurrence of mental disorders during pregnancy, prompts to focus on the problem of appropriate care for future mothers, not only in physical terms. An important issue is the standardization of diagnostic procedures and the dissemination of screening tests for maternity depression.

Key words: pregnancy; maternity depression; postpartum depression

\section{Introduction and purpose}

Major depressive disorder (MDD) is characterized mainly by depressive mood and anhedonia, which is described as impaired ability to feel pleasure. ${ }^{1}$ These symptoms may occur alone or in combination. Other possible accompanying conditions include for example chronic fatigue, insomnia or decreased interest in being active in life $^{2}$ It is estimated that women are approximately twice as likely to develop MDD symptoms in their lifetime as men. ${ }^{1}$ The aim of the study is to present the impact of depression in mothers on the mental and physical health of children and to describe the issues related to the diagnosis of this disease. To achieve this objective Pubmed database was searched using words such as perinatal depression, postpartum depression, pregnancy.

\subsection{Epidemiology}

Pregnancy may increase the risk of depressive episodes. ${ }^{3}$ It is estimated that the risk of developing mental disorders at various stages of pregnancy is approximately $12.7 \%^{2}$ and depends, inter alia, on the level of development of a given country ${ }^{4}$ or its culture. ${ }^{5}$ A metaanalysis by Woody et al. showed that women in low and middle income countries develop perinatal depressive disorders more often than women who live in high income countries (13.2\%, 95\% confidence interval [CI] 12.2-14.1 and respectively $11.4 \%, 95 \%$ CI 10.8-12.1). ${ }^{6}$ In developed countries, the prevalence of only MDD in pregnant women ranges from $1.0 \%$ to $5.6 \%$. Taking into account the coexistence of major and minor depression, the incidence ranges from $6.5 \%$ to $12.9 \%{ }^{7}$ 
However, it is postulated that the results of the current analyzes may not fully reflect the scale of the global problem of depression in women during and after pregnancy. ${ }^{4}$

\subsection{Pathogenesis and risk factors}

The cause of depressive disorders in women during pregnancy is multifactorial. Considering the genetic background, the occurrence of perinatal depression (PND) may be related, inter alia, to the polymorphism of the gene encoding the Brain Derived Neutrophic Factor (BDNF). Another issue worth considering is the increased sensitivity to estrogen signaling in women with postpartum depression (PDD), associated with the estrogen receptor alpha gene (ESR1) polymorphism. ${ }^{8}$

Among the risk factors for PND, the strongest of these are depressive disorders in the mother's history. About $90 \%$ of people who have ever had an episode of depression will experience it again in the future. ${ }^{9}$ Other factors that influence the development of PND are, among others, single motherhood, low income, age below 20 years, tobacco abuse, insufficient support from the society or domestic violence. ${ }^{9}$

It has also been shown that pregnant women who suffer from obesity are more likely to develop depressive symptoms both during pregnancy and in the postpartum period. Obesity and depression are independent predictors of various health consequences for both mother and child. It is postulated that the common occurrence of these two factors may exacerbate these negative effects. ${ }^{10}$ It is speculated that a higher risk of developing depressive symptoms during pregnancy and postpartum is influenced by lower maternal vitamin D levels. ${ }^{11,12}$ Studies have also found an association between the development of PDD and the use of methyldopa, the drug of first choice in Pregnancy-induced hypertension (PIH). ${ }^{13}$

Depressive symptoms and anxiety occurring during pregnancy are, in turn, one of the strongest risk factors for postpartum depression. Factors such as the socioeconomic status of the family, physical violence and health complications related to the course of pregnancy and childbirth are also important. The history of premenstrual dysphoric disorder (PMDD) and mood disorders related to the use of oral contraceptives by a woman positively correlates with the risk of PDD. ${ }^{14}$

\subsection{Diagnosis}

Major depressive disorder (MDD) can be defined as having a history of depressed mood or decreased pleasure in the patient's history for at least 2 weeks, combined with at least 5 of the symptoms listed below. ${ }^{15}$ (Table 1 ) 
Table 1. DSM-5 Criteria for Major Depressive Episode

\begin{tabular}{l|l}
1 & $\begin{array}{l}\text { Significant fluctuation in body weight (more than } 5 \% \text { weight gain or loss in a month } \\
\text { without following a special diet) }\end{array}$ \\
\hline 2 & Insomnia or hypersomnia \\
\hline 3 & Psychomotor symptoms ( e.g., agitation, retardation) \\
\hline 4 & Fatigue, loss of energy \\
\hline 5 & Feelings of worthlessness, guilt or helplessness \\
\hline 6 & Difficulties in coherent thinking and decision-making \\
\hline 7 & Recurring thoughts of death, suicide
\end{tabular}

Perinatal depression (PND) is defined as an episode of minor or major depression with onset during pregnancy or within the 12-month period postpartum. ${ }^{16}$ In 2000 , the Diagnostic and Statistical Manual of Mental Disorders - Fourth Edition (DSM-IV) specified the term postpartum depression (PDD) as a disorder that occurs within 4 weeks after delivery. ${ }^{17}$ In turn, in 2013, DSM-5 extended this time to 6 months after delivery, taking into account clinical reports. ${ }^{15}$ In addition to taking into account the time frame of the occurrence of symptoms, it is also important to properly classify them. During and after pregnancy, due to changes in the physiology of the pregnant woman, including fluctuations in the hormonal balance, future mothers manifest a number of symptoms that may be misinterpreted. These women often suffer from mood swings, changes in appetite, less energy and sleep disturbances. ${ }^{18}$ A particularly common Condition that requires differentiation from PND is socalled "postnatal blues" (also called "baby blues" ${ }^{16}$ or ,,maternity blues”). ${ }^{19}$ It is characterized by mild mood swings and a transient nature. It usually occurs three to five days after giving birth. ${ }^{20}$ Rezaie-Keikhai et. al, taking into account the results of 26 studies, estimated that the prevalence of maternity blueas ranges from $13.7 \%$ to even $76.0 \%$ and depends on the country income. ${ }^{19}$ In addition, a prospective study by Zanardo et al. Found an association between a high Maternity Blues Scale (MBS) score and the Edinburgh Postnatal Depression Scale (EPDS) score $(\mathrm{r}=0.22, \mathrm{p}<0.001){ }^{21}$ PND also requires differentiation with postpartum psychosis, which is much rarer than maternity blues. Its prevalence ranges from about $0.1 \%$ to $0.5 \%{ }^{18}$ Symptoms associated with postpatrum psychosis include, among others, labile mood, agitation, delusions, hallucinations, and loss of control that can lead to harm to both mother and baby. ${ }^{22}$ Due to the difficulty in diagnosis and the lack of standardized screening tests in the world it is Estimated that up to $50 \%$ of postnatal depression cases stay undiagnosed. ${ }^{4}$

\section{Description of the state of knowledge}

\subsection{The impact of maternal depression on various aspects of child health}

Depression that occurs during pregnancy, in addition to the obvious impact on the mental health of the mother, also has a significant impact on the fetal development and later functioning of the child. ${ }^{3,10,23}$

The fetuses of mothers who were depressed during pregnancy have weaker and slower response to external stimuli, showing less pronounced changes in heart rate after stimulation compared to control groups. At the same time, given the overall activity, the fetuses of depressed mothers were hyperactive and alerted for a greater amount of time. ${ }^{3}$ 
One of the most serious complications of PND is premature termination of pregnancy and the often associated low birth weight. Kramer et. al. conducted an extensive prospective study on a group of 5,337 women who were followed up around 24-26 weeks of pregnancy. Depressive symptoms were investigated using the Centerfor Epidemiologic Studies Depression (CES-D) Scale. Achieving a score of $\geq 16$ was tantamount to assessing symptoms as depressive. In addition to the scale of depressive disorders, there were also assessed pregnancy-related anxiety, job-related stress, self-esteem and woman's perception of risk of birth complications. Anxiety related to pregnancy was measured using the Likert 5-point scale, which monitors how often a woman felt anxiety, worry, fear or panic about being pregnant. Among the factors studied, depressive symptoms, anxiety caused by being pregnant and perceiving the risk of perinatal complications as significant influenced spontaneous preterm birth. Women who achieved the CES-D score $\geq 16$ points showed a $40 \%$ higher risk of preterm labor than women who scored $\leq 15$ points $(\mathrm{OR} 1 / 41.4[95 \% \mathrm{CI} 1 / 41.01,2.1]){ }^{24}$

Depressive disorders during pregnancy are also associated with changes in the central nervous system (CNS) and include, among others, structural changes in the prefrontal cortex and the amygdala. It is speculated that the mechanism responsible for the above-mentioned changes may be hormonal changes in the mother's body during PND, in particular the increased level of cortisol in the bloodstream. ${ }^{10}$ The placenta is a key barrier to the entry of excess glucocorticosteroids into the fetus. ${ }^{25}$ The 11-beta-hydroxysteroid dehydrogenase type 2 (11ß-HSD-2) enzyme converts the active form of cortisol into its passive form. However, some studies show that the activity of this enzyme can be significantly lowered when the mother suffers from depression or excessive stress. ${ }^{26,27}$ Glucocorticoid levels are closely related to the activity of pro-inflammatory cytokines in the body, which may result in neurodevelopmental consequences. This has a negative impact on the development of the fetus and induces negative changes in the emotional and cognitive spheres later in life. ${ }^{28}$

Newborns born to mothers who exhibited depressive disorders during pregnancy tended to present stressful behavior and crying more often compared to those born to healthy mothers or mothers only with postpartum depression. ${ }^{29}$ A study by Ip et. al has shown that PDD results in a weak emotional bond between the parent and the child, which is manifested, for example, by reduced patience and tolerance towards the child. ${ }^{30}$ Mothers suffering from depression are less likely to touch their children with tenderness and show a reduced willingness to interact with the child, including on a smile or telling stories. ${ }^{31}$ It was also shown there is a correlation between maternal depression during pregnancy and the quality of mental health of the child, even after reaching maturity. People whose mothers have suffered from maternal depression are 3 to 4 times more likely to experience psychosocial and environmental problems in adulthood. ${ }^{10}$

A relationship is also seen in PND and the use of antidepressants with the occurrence of autism spectrum disorders in children. ${ }^{14}$ Newborns from mothers who took selective serotonin reuptake inhibitors (SSRI) for depression treatment during pregnancy have also been shown to have a higher risk of developing persistent pulmonary hypertension of the newborn (PPHN). ${ }^{14}$ 


\section{Summary}

Maternity depression is still an important diagnostic challenge. Despite the knowledge of many predisposing factors, many cases remain undiagnosed. It has serious consequences, including premature birth, CNS development disorders, less intimate parent-child relationship and predisposes to behavioral and cognitive disorders later in life. Research also indicates that babies of mothers who suffered from depressive symptoms during pregnancy are at a higher risk of developing depression in the future. The severe effects of maternity depression are reason why it is worth investigating possible preventive measures.

\section{References:}

1. Labaka A, Goñi-Balentziaga O, Lebeña A, Pérez-Tejada J. Biological Sex Differences in Depression: A Systematic Review. Biological Research For Nursing. 2018;20(4):383-392. doi:10.1177/1099800418776082

2. Angelotta C, Wisner KL. Treating Depression during Pregnancy: Are We Asking the Right Questions? Birth Defects Research. 2017;109(12):879-887. doi:10.1002/bdr2.1074

3. Gentile S. Untreated depression during pregnancy: Short- and long-term effects in offspring. A systematic review. Neuroscience. 2017;342:154-166. doi:10.1016/j.neuroscience.2015.09.001

4. Payne JL, Maguire J. Pathophysiological mechanisms implicated in postpartum depression. Frontiers in Neuroendocrinology. 2019;52:165-180. doi:10.1016/j.yfrne.2018.12.001

5. Abdollahi F, Lye MS, Zain AM, Ghazali SS, Zarghami M. Postnatal depression and its associated factors in women from different cultures. Iranian Journal of Psychiatry and Behavioral Sciences. 2011;5(2):511. /pmc/articles/PMC3939973/?report=abstract. Accessed August 29, 2020.

6. Woody CA, Ferrari AJ, Siskind DJ, Whiteford HA, Harris MG. A systematic review and metaregression of the prevalence and incidence of perinatal depression. Journal of Affective Disorders. 2017;219:8692. doi:10.1016/j.jad.2017.05.003

7. LEARMAN LA. Screening for Depression in Pregnancy and the Postpartum Period. Clinical Obstetrics and Gynecology. 2018;61(3):525-532. doi:10.1097/GRF.0000000000000359

8. Serati M, Redaelli M, Buoli M, Altamura AC. Perinatal Major Depression Biomarkers: A systematic review. Journal of Affective Disorders. 2016;193:391-404. doi:10.1016/j.jad.2016.01.027

9. Stewart DE. Depression during Pregnancy. New England Journal of Medicine. 2011;365(17):16051611. doi:10.1056/NEJMcp1102730

10. Cattane N, Räikkönen K, Anniverno R, et al. Depression, obesity and their comorbidity during pregnancy: effects on the offspring's mental and physical health. Molecular Psychiatry. July 2020. doi:10.1038/s41380-020-0813-6

11. Trujillo J, Vieira MC, Lepsch J, et al. A systematic review of the associations between maternal nutritional biomarkers and depression and/or anxiety during pregnancy and postpartum. Journal of Affective Disorders. 2018;232:185-203. doi:10.1016/j.jad.2018.02.004

12. Williams JA, Romero VC, Clinton CM, et al. Vitamin D levels and perinatal depressive symptoms in women at risk: a secondary analysis of the mothers, omega-3, and mental health study. BMC Pregnancy and Childbirth. 2016;16(1):203. doi:10.1186/s12884-016-0988-7

13. Wiciński M, Malinowski B, Puk O, Socha M, Słupski M. Methyldopa as an inductor of postpartum depression and maternal blues: A review. Biomedicine \& Pharmacotherapy. 2020;127:110196. doi:10.1016/j.biopha.2020.110196

14. Becker M, Weinberger T, Chandy A, Schmukler S. Depression During Pregnancy and Postpartum. Current Psychiatry Reports. 2016;18(3):32. doi:10.1007/s11920-016-0664-7

15. American Psychiatric Association. American Psychiatric Association: Diagnostic and Statistical Manual of Mental Disorders Fifth Edition.; 2013. doi:10.1176/appi.books.9780890425596.744053

16. Milgrom J, Gemmill AW. Screening for perinatal depression. Best Practice \& Research Clinical Obstetrics \& Gynaecology. 2014;28(1):13-23. doi:10.1016/j.bpobgyn.2013.08.014

17. American Psychiatric Association. American Psychiatric Association: Diagnostic and Statistical Manual of Mental Disorders, Fourth Edition, Text Revision. American Psychiatric Association. 2000. 
doi:10.1176/appi.books. 9780890423349

18. O'Hara MW, McCabe JE. Postpartum Depression: Current Status and Future Directions. Annual Review of Clinical Psychology. 2013;9(1):379-407. doi:10.1146/annurev-clinpsy-050212-185612

19. Rezaie-Keikhaie K, Arbabshastan ME, Rafiemanesh H, Amirshahi M, Ostadkelayeh SM, Arbabisarjou A. Systematic Review and Meta-Analysis of the Prevalence of the Maternity Blues in the Postpartum Period. Journal of Obstetric, Gynecologic \& Neonatal Nursing. 2020;49(2):127-136. doi:10.1016/j.jogn.2020.01.001

20. Buttner MM, O'Hara MW, Watson D. The Structure of Women's Mood in the Early Postpartum. Assessment. 2012;19(2):247-256. doi:10.1177/1073191111429388

21. Zanardo V, Volpe F, de Luca F, et al. Maternity blues: a risk factor for anhedonia, anxiety, and depression components of Edinburgh Postnatal Depression Scale. The Journal of Maternal-Fetal \& Neonatal Medicine. March 2019:1-7. doi:10.1080/14767058.2019.1593363

22. VanderKruik R, Barreix M, Chou D, Allen T, Say L, Cohen LS. The global prevalence of postpartum psychosis: a systematic review. BMC Psychiatry. 2017;17(1):272. doi:10.1186/s12888-017-1427-7

23. Pearlstein T. Depression during Pregnancy. Best Practice \& Research Clinical Obstetrics \& Gynaecology. 2015;29(5):754-764. doi:10.1016/j.bpobgyn.2015.04.004

24. Kramer MS, Lydon J, Séguin L, et al. Stress pathways to spontaneous preterm birth: The role of stressors, psychological distress, and stress hormones. American Journal of Epidemiology. 2009;169(11):13191326. doi:10.1093/aje/kwp061

25. Räikkönen K, Pesonen A-K, O'Reilly JR, et al. Maternal depressive symptoms during pregnancy, placental expression of genes regulating glucocorticoid and serotonin function and infant regulatory behaviors. Psychological Medicine. 2015;45(15):3217-3226. doi:10.1017/S003329171500121X

26. Seth S, Lewis A, Saffery R, Lappas M, Galbally M. Maternal Prenatal Mental Health and Placental 11ßHSD2 Gene Expression: Initial Findings from the Mercy Pregnancy and Emotional Wellbeing Study. International Journal of Molecular Sciences. 2015;16(11):27482-27496. doi:10.3390/ijms161126034

27. O'Donnell KJ, Bugge Jensen A, Freeman L, Khalife N, O'Connor TG, Glover V. Maternal prenatal anxiety and downregulation of placental 11ß-HSD2. Psychoneuroendocrinology. 2012;37(6):818-826. doi:10.1016/j.psyneuen.2011.09.014

28. Sandman CA, Davis EP. Neurobehavioral risk is associated with gestational exposure to stress hormones. Expert Review of Endocrinology \& Metabolism. 2012;7(4):445-459. doi:10.1586/eem.12.33

29. Diego MA, Field T, Hernandez-Reif M, Cullen C, Schanberg S, Kuhn C. Prepartum, Postpartum, and Chronic Depression Effects on Newborns. Psychiatry: Interpersonal and Biological Processes. 2004;67(1):6380. doi:10.1521/psyc.67.1.63.31251

30. Ip P, Li TMH, Chan KL, et al. Associations of paternal postpartum depressive symptoms and infant development in a Chinese longitudinal study. Infant Behavior and Development. 2018;53:81-89. doi:10.1016/j.infbeh.2018.08.002

31. Brummelte S, Galea LAM. Postpartum depression: Etiology, treatment and consequences for maternal care. Hormones and Behavior. 2016;77:153-166. doi:10.1016/j.yhbeh.2015.08.008 